\title{
Avaliação da atividade antimicrobiana de pigmentos extracelulares produzidos por fungos endofíticos
}

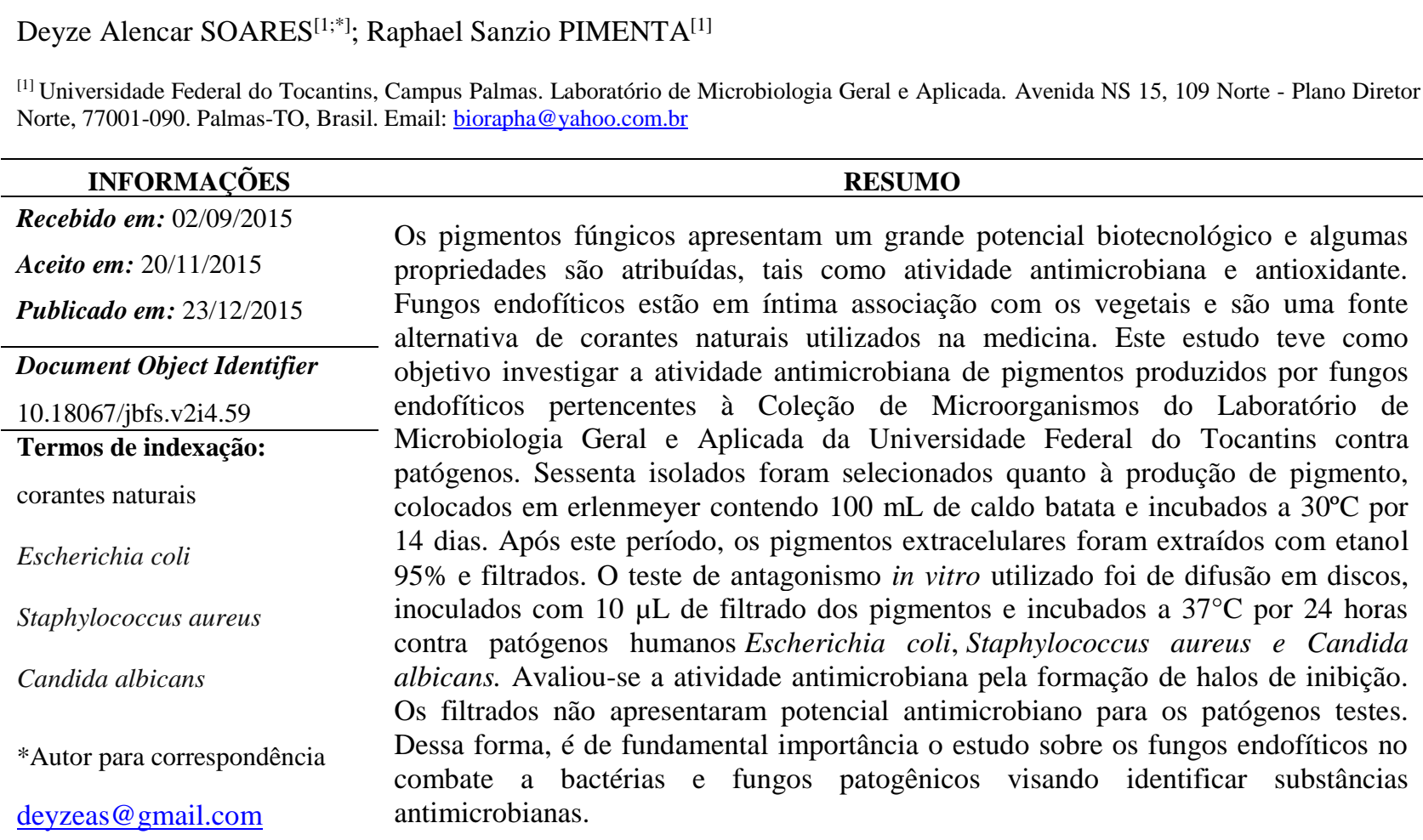

\section{Evaluation of antimicrobial activity from extracellular pigments produced by endophytic}

\begin{abstract}
Fungi pigments have a great biotechnological potential and some properties such as antimicrobial and antioxidant activity. Fungal endophytes are closely associated with plants and are an alternative source of natural dyes, which can be used in medicine. This study aimed to investigate the antimicrobial activity of pigments produced by endophytic fungi against pathogens. They belonged to the Microorganisms Collection of the General and Applied Microbiology Laboratory at the Federal University of Tocantins. Firstly, sixty isolated samples were selected accordingly to pigment production, then they were placed in an Erlenmeyer containing $100 \mathrm{ml}$ of potato broth and incubated at $30^{\circ} \mathrm{C}$ for 14 days. After this period, the extracellular pigments were extracted with $95 \%$ ethanol and subsequently they were filtered. Diffusion disks were used in the in vitro antagonism test, which were inoculated with $10 \mathrm{uL}$ of pigment filtrates and incubated at $37^{\circ} \mathrm{C}$ for 24 hours against human pathogens, for instance, Escherichia coli, Staphylococcus aureus and Candida albicans. The antimicrobial activity was evaluated based on the formation of an inhibition zone. The filtrates have not showed antimicrobial potential based on the pathogens tests. Therefore, the endophytic fungi study aiming to identify antimicrobial substances is fundamentally important against bacteria and pathogenic fungi.
\end{abstract}

Index terms: natural dyes, Escherichia coli, Staphylococcus aureus, Candida albicans

\section{(i) (2)} provided the

Copyright: (c) 2015 JBFS all rights. This is an open-access article distributed under the terms of the Creative Commons Attribution License, which permits unrestricted use, distribution, and reproduction in any medium, riginal author and source are credited.

Financiamento: Os autores reportam que houve suporte e auxílio financeiro pela Coordenação de Aperfeiçoamento de Pessoal de Nível Superior (CAPES)

Conflito de interesse: Os autores declaram que não há conflito de interesse.

Como referir esse documento (ABNT):

SOARES, D. A.; PIMENTA, R S. Avaliação da atividade antimicrobiana de pigmentos extracelulares produzidos por fungos endofíticos. Journal of Bioenergy and Food Science, Macapá, v.2, n.4, p.152-155, out./dez., 2015. http://dx.doi.org/10.18067/jbfs.v2i4.59 


\section{INTRODUÇÃO}

O crescente número de microrganismos resistentes às drogas tem instigado os pesquisadores a buscarem por novas opções terapêuticas [1]. Segundo Guo et al. [2], o surgimento de doenças antes inexistentes e de microrganismos multiresistentes geralmente vêm acompanhados do crescente aumento da degradação ambiental, perda de biodiversidade e contaminação dos ambientes terrestres e aquáticos.

Os microrganismos, em especial os fungos, são fontes promissoras de substâncias naturais bioativas [3, 4]. Inúmeros medicamentos comercializados e utilizados atualmente na prática clínica são derivados de metabólitos secundários produzidos por fungos [5-8].

Fungos endofíticos colonizam os tecidos internos de espécies vegetais, e apresentam uma importante interação com seus hospedeiros, podem produzir uma gama de moléculas bioativas com enorme potencial de serem exploradas quanto às suas ações farmacológicas [9, 10]. Estudos demonstraram que em plantas medicinais os microrganismos endofíticos produzem metabólitos secundários que possuem uma atividade biológica similar à atribuída à planta que coloniza [11-16].

Como uma forma de estabelecer o papel funcional dos fungos endofíticos se faz necessário, dentre outros fatores, a detecção de pigmentos extracelulares [17]. Os fungos endofíticos podem produzir pigmentos como mecanismos de resistência para superar as defesas do hospedeiro contra invasão microbiana [6].

Há poucos estudos relacionados à produção de pigmentos por microorganismos. A produção de pigmentos fúngicos consiste em uma área nova, em expansão e apresenta um potencial biotecnológico muito atraente [17]. Fungos do gênero Monascus são conhecidos pela habilidade de produzir pigmentos amarelos, laranjas e vermelhos que tem sido utilizado tradicionalmente por países asiáticos como corantes de alimentos [18-20]. Atualmente existe uma grande demanda para a descoberta e uso de novos pigmentos de origem natural em produtos alimentícios, cosméticos e em processos farmacêuticos [21]. Isso se deve a preocupação dos efeitos prejudiciais dos pigmentos sintéticos em humanos e ao ambiente [22, 23].

Alguns corantes sintéticos são considerados responsáveis por reações alérgicas e intolerâncias, além de outros efeitos tóxicos como mutagenicidade e potencial carcinogênico [24]. Outras propriedades que podem ser atribuídas aos pigmentos fúngicos, tais como atividade antimicrobiana, citototoxidade a células tumorais, antioxidante e agir como cofatores em catálises enzimáticas [25].

Fungos com potencial na produção de pigmentos não devem ser patogênicos [26]. Além disso, devem satisfazer alguns critérios como: capacidade de utilizar uma grande variedade de fontes de carbono e nitrogênio, apresentar tolerância a diferentes valores de $\mathrm{pH}$, temperaturas e minerais e produzir pigmentos em quantidade razoável [27].

Apesar de vários estudos relacionados à produção de metabólitos importantes, poucos foram realizados para a obtenção de pigmentos naturais. Neste contexto, o presente trabalho propõe-se apresentar atividade antimicrobiana por filtrados fúngicos de alguma espécie de fungos endofíticos.

\section{MATERIAL E MÉTODOS}

Sessenta isolados foram selecionados quanto à produção de pigmentos. Um fragmento da cultura que se encontrava armazenada em microtubos, pelo método de Castelani, foi transferido para placas de Petri contendo meios Ágar Batata Dextrose (BDA). Ao final de 14 dias detectou a produção de pigmentos extracelulares.

Os fungos produtores de pigmentos foram colocados em erlenmeyer contendo $100 \mathrm{~mL}$ de caldo batata e incubados a $30^{\circ} \mathrm{C}$ por 14 dias. Após este período, foram submetidos à agitação de 100 rpm à temperatura ambiente por 1 hora e os pigmentos extracelulares foram extraídos com etanol $95 \%$ e filtrados.

$\mathrm{O}$ teste de antagonismo in vitro utilizado foi de difusão em discos, contra patógenos humanos Escherichia coli, Staphylococcus aureus e Candida albicans. Em placas de Petri com meio Mueller Hinton contendo os patógenos, foram inseridos discos de papel estéreis inoculados com $10 \mu \mathrm{L}$ de filtrado dos pigmentos e incubadas a $37^{\circ} \mathrm{C}$ por 24 horas. Os controles negativos foram realizados com a inoculação de antibióticos e antifúngicos em concentrações semelhantes às dos filtrados. Todos os testes foram realizados em triplicata.

As leituras foram realizadas mensurando os halos de inibição das bactérias testadas com 24 horas de crescimento. As medidas obtidas foram avaliadas estatisticamente por meio de análise de variância (ANOVA) e as médias comparadas pelo teste de Tukey $(\mathrm{p}<0,05)$ com auxílio do programa estatístico SAS [28].

\section{RESULTADOS E DISCUSSÃO}

O uso de pigmentos originários dos isolados não foi capaz de inibir o crescimento dos patógenos testados, em concentrações semelhantes às dos 
antibióticos-controle utilizados. $\mathrm{Li}$ et al. [29] avaliaram a produção de substâncias bioativas por 32 isolados endofíticos de Cynodon dactylon. O extrato do isolado endofítico Aspergillus sp. foi ativo para bactérias Gram-positivas e Gramnegativas. De forma geral, os resultados contribuem para evidenciar os fungos endofíticos como alvos para futuros estudos visando identificar novos agentes antimicrobianos.

\section{CONCLUSÕES}

A produção de pigmentos por microrganismos é uma alternativa ao aumento da produção destes compostos naturais frente aos sintéticos. Logo, o descobrimento de novas tecnologias e o estudo de condições para produção destes pigmentos merece grande atenção, podendo ser útil futuramente na indústria farmacêutica para o controle de patógenos.

\section{AGRADECIMENTOS}

À Cristiane Martins Coelho e Marcia Regina Oliveira Marson por colaborações pessoais, e CAPES (Coordenação de Aperfeiçoamento de Pessoal de Nível Superior) por apoio financeiro.

\section{CONTRIBUIÇÃO DOS AUTORES}

1. Condução e contribuição na elaboração do artigo:

\section{Deyze Alencar Soares}

2. Planejamento, orientação e revisão final do artigo:

Dr. Raphael Sanzio Pimenta

\section{REFERÊNCIAS}

[1]. STROBEL, G.; DAISY, B. Bioprospecting for microbial endopytes and their natural products. Microbiology and Molecular Biology Review. v.67, n.4, p.491-502, 2003. DOI:10.1128/MMBR.67.4.491-502.2003.

[2]. GUO, B.; WANG, Y.; SUN, X.; TANG K. Bioactive natural products from endophytes: a review. Applied Biochemistry and Microbiology, v.44, n.2, p.136-142, 2008. DOI:10.1134/S0003683808020026.

[3]. STONE, J.K.; C.W. BACON; J.F. WHITE. An Overview of Endophytic Microbes Endophytism Defined. In: Microbial Endophytes, Bacon C.W. and J.F. White (Eds.). Marcel Dekker, New York, 3-29, 2000

[4]. CONTI, R.; GUIMARÃES, D.O.; PUPO, M.T. Aprendendo com as interações da natureza: microrganismos simbiontes como fontes de produtos naturais bioativos. Ciência e Cultura. v.64, n.3, p.43-47, 2012.

[5]. ARNOLD, A. E.; MAYNARD, Z.; GILBERT, G. S.; COLEY, P. D.; T. A. KURSAR. Are tropical fungal endophytes hyperdiverse? Ecology Letters. v.3, n.4, p.267-274, 2000. DOI:10.1046/j.14610248.2000.00159.x.

[6]. TAN, R. X.; ZOU, W. X. Endophytes: a rich source of functional metabolites. Natural Product Reports. v.18, n.4, p.448-59, 2001. DOI:10.1039/B100918O

[7]. STROBEL, G.A. Endophytes as sources of bioactive products. Microbes Infection. v.5, n.6,
p.535-544, 2003.
4579(03)00073-X

[8]. FERRARA, M.A. Fungos Endofíticos. Potencial para a Produção de Substâncias Bioativas. Revista Fitos, v.2, n.1, p.73-79, 2006.

[9]. STROBEL, G.; DAISY, B. Bioprospecting for microbial endopytes and their natural products. Microbiology and Molecular Biology Review. v.67, n.4, p.491-502, 2003. DOI:10.1128/MMBR.67.4.491-502.2003

[10]. SCHULZ, B.; BOYLE, C. The endophytic continuum. Mycological Research. v.109, n.6, p.661-686, 2005.

DOI:10.1017/S095375620500273X

[11]. ROSA, L.H.; MACHADO, K.M.G.; JACOB, C.C.; CAPELARI, M.; ROSA, C.A.; ZANI, C.L. Screening of brazilian basidiomycetes for antimicrobial activity. Memórias do Instituto Oswaldo Cruz, v.98, n.7, p.967-974, 2003. DOI:10.1590/s0074-02762003000700019

[12]. EYBERGER, A.L.; DONDAPATI, R.; J.R. PORTER, Endophyte fungal isolates from Podophyllum peltatum produce podophyllotoxin. Journal of Natural Products, v.69, n.8, p.11211124, 2006. DOI:10.1021/np060174f

[13]. PURI, S.G., V. VERMA, T. AMNA, G.N. QAZI AND M. SPITELLER. An endophytic fungus from Nothapodytes foetida that produces camptothecin. Journal of Natural Products., v.68, n.12, p.1717-1719, 2005. DOI:10.1021/np0502802

[14]. SCHWAB, E.K.; KELLER, N.P. Regulation of secondary metabolite production in filamentous 
ascomycetes. Mycological Research. v.112, p.225-230, 2008.

DOI:10.1016/j.mycres.2007.08.021

[15]. KUSARI, S.; LAMSHOFT, M.; ZUHLKE, S.; SPITELLER, M. An endophytic fungus from Hypericum perforatum that produces hypericin. Journal of Natural Products, v.71, n.2, p.10591063, 2008. DOI:10.1021/np070669k

[16]. PINTO, W. S.; ROSA, L. H.; SILVA, J. F. M.; PERIM, M. C.; BORGES, J. C.; JANIEWICZ, W. J. ; PIMENTA, R. S. Diversity and Antimicrobial Activities of Endophytic Fungi Isolated from Myrcia Sellowiana in Tocantins, Brazil. Hortscience, v.905, p.283-286, 2011. DOI:10.17660/ActaHortic.2011.905.31

[17]. DURÁN, N.; TEIXEIRA, M.F.S.; ESPOSITO, E. Pigmentos fúngicos e seu potencial biotecnológico. In: Esposito, E.; Azevedo J.L. Fungos: uma introdução à biologia, bioquímica e biotecnologia, EDUCS. 290-307, Caxias do Sul, 2004.

[18]. FENICE, M.; FEDERICI, F.; SELBMANN, L.; PETRUCCIOLI, M. Repeated-batch production of pigments by immobilised Monascus purpureus. Journal of Biotechnology. v.80, n.3, p.271-276, 2000. DOI:10.1016/S01681656(00)00271-6

[19]. HAJJAJ, H.; BLANC, P.; GROUSSAC, E.; URIBELARREA, J. L.; GOMA, G.; LOUBIERE, $P$. Kinetic analysis of red pigment and citrinin production Monascus ruber as a function of organic acid accumulation. Enzime and Microbial Technology. v.27, n.8, p.619-625, 2000. DOI:10.1016/s0141-0229(00)00260-x

[20]. PATTANAGUL, P.; PINTHONG, R.; PHIANMONGKHOL, A.; TARATHA, S. Mevinolin, cetrinin and pigments of adlay angkak fermented by Monascus sp. International Journal of Food Microbiology, v.126, p.20-23, 2008. DOI:10.1016/j.ijfoodmicro.2008.04.019

[21]. CHO, Y.J.; HWANG, H.J.; SONG, C.H.; YUN, J. W. Effect of carbon source and aeration rate on broth rheology and fungal morphology during red pigment production by Paecilomyces sinclairii in a batch bioreactor. Journal of Biotechnology, v.95, n.1, p.13-23, 2002. DOI:10.1016/S0168-1656(01)00445-X

[22]. NAGIA, F.A.; EL-MOHAMEDY, R.S.R. Dyeing of wool with natural anthraquinone dyes from Fusarium oxysporum, Dyes and Pigments, v.75, n.3, p.550-555, 2007. DOI:10.1016/j.dyepig.2006.07.002

[23]. SIVAKUMAR, V.G.; SHANKAR, P; NALINA, K.; MENON, T. Use of CHRO Magar in the Differentiation of Common Species of Candida. Mycopathologia, v.167, n.1, p.47-49, 2009. DOI:10.1007/s11046-008-9149-5

[24]. BLENFORD, D. Bioavailability is Key to Nutrient Effectiveness'. Food Ingredients and Processing International. v.17, p.28-30, 1995.

[25]. MAPARI, S.A.; NIELSEN, K.F.; LARSEN, T.O.; FRISVAD, J.C.; MEYER, A.S.; THRANE, U. Exploring fungal biodiversity for the production of water-soluble pigments as potential natural food colorants. Current Opinion in Biotechnology. v.16, n.2, p.231-238, 2005. DOI:10.1016/j.copbio.2005.03.004

[26]. DUFOSSÉ, L.; GALAUP, P.; YARON, A.; ARAD, S. M.; BLANC, P.; MURTHY, K. N. C.; RAVISHANKAR. Microorganisms and microalgae as sources of pigments for food use: a scientific oddity or an industrial reality? Trends in Food Science \& Technology. v.16, n.9, p.389406, 2005. DOI:10.1016/j.tifs.2005.02.006.

[27]. LÓPEZ, P. V. A. Bioprospecção de extratos de Croton Urucurana Baill e seus fungos endofíticos. Tese de Doutorado, Universidade Federal do Paraná, 2010.

[28]. SAS. Statistical Analysis System. SAS Institute Inc., Cary, NC, USA, 2001

[29]. LI, Y.; SONG, J.Y.; LIU, J.Y. AntiHelicobacter pylori substances from endophytic fungal cultures. World Journal of Microbiology and Biotechnology. v.21, n.4, p.553-558, 2005. DOI:10.1007/s11274-004-3273-2. 